\title{
ФОРМИРОВАНИЕ МОЛОДЕЖНОЙ ПОЛИТИКИ В СФЕРЕ ОБРАЗОВАНИЯ, НАУКИ И ИННОВАЦИЙ: ЗАРУБЕЖНЫЙ ОПЫТ СТРАН БРИКС
}

\section{FORMATION OF YOUTH POLICY IN THE FIELD OF EDUCATION, SCIENCE AND INNOVATION: REVIEW OF THE BRICS COUNTRIES}

\section{Melnichuk}

State youth policy is a system of priorities and measures designed to create conditions and opportunities for successful socialization and selfrealization of youth, development of its potential in the interests of the country. The formation and modernization of the state's youth policy is not an autonomous process, but a process that synthesizes a number of factors that can lead to the solution of strategic state tasks for the transition to a knowledge economy, and, as a result, to sustainable economic growth. The author has studied the international experience of the formation and implementation of youth policy in the field of education and innovation, carried out by the BRICS countries in recent decades, which seems informative and indicative, since in the Russian Federation there is a single information space summarizing data on youth policy activities, including in the field of science and technology, today is not formed.

Keywords: youth policy, youth development, strategic plan, youth organization, youth projects funding.
$\mathbf{P}$ егулирование и модернизация государственной молодежной политики становится одним из ключевых элементов формирования экономики знаний, в которой основным приоритетом является человеческий капитал [1, 3]. Опыт стран БРИКС интересен с той точки зрения, что на протяжении последних десятилетий эти государства активно занимаются модернизацией своих экономик посредством активизации инновационной деятельности и создания собственных инноваций на базе наращивания кадрового потенциала [2].

Так, в Бразилии в числе первоочередных документов, регламентирующих молодежную политику этой страны, затрагивающих вопросы науки, техники и инноваций и нацеленных на поддержку деятельности молодежи Бразилии в предпринимательской и инновационной сферах, следует выделить:

- Конституцию Бразилии, в которой ст. 227 гласит о необходимости учета интересов молодежи;

\author{
Мельничук Марина Владимировна \\ Д.э.н., к.п.н., профессор, Финансовый университет \\ при Правительстве Российской Федерачии \\ mvmelnichuk@gmail.com
}

Аннотация. Государственная молодежная политика является системой приоритетов и мер, призванных создать условия и возможности для успешной социализации и самореализации молодежи, развития ее потенциала в интересах страны. Формирование и модернизация молодежной политики государства — это не автономный процесс, а процесс, синтезирующий целый ряд факторов, способных привести к решению стратегических государственных задач по переходу к экономике знаний, и, как следствие, к устойчивому экономическому росту. Автором изучен международный опыт формирования и имплементации молодежной политики в сфере образования и инноваций, проводимой странами БРИКС в последние десятилетия, что представляется информативным и показательным, так как в Российской Федерации единое информационное пространство, обобщающее данные о мероприятиях молодежной политики, в том числе в области науки и техники, на сегодняшний день не сформировано.

Ключевые слова: молодежная политика, развитие молодежи, стратегический план, молодежная организация, финансирование молодежных проектов.

- Национальный молодежный план;

- Национальный план развития стартапов для молодежи на 2018-2020 гг. (создан Национальным молодежным секретариатом в партнерстве с ОOH по вопросам образования, науки и культуры) [5];

- Молодежный устав (принят 5 августа 2013 года), регламентирующий права молодых бразильцев, в том числе: право на равенство, право на спорт и отдых, на общение и свободу мысли, на культуру, на общественную безопасность, на доступ к правосудию, на гражданство, социальное и политическое участие в жизни общества, профессиональную деятельность, здоровье, образование и устойчивое развитие [4].

Целями реализации Национального плана являются: получение образования в области предпринимательства и ведения бизнеса; получение дополнительного 
образования студентов в форме мастер-классов и дисциплин, включающих изучение предпринимательской деятельности; сокращение времени для открытия собственного бизнеса; привлечение финансирования; распространение знаний о государственной молодежной политике в области предпринимательства и др.

Благодаря реализации мероприятий Национального плана, бразильская молодежь вовлекается в инновационные методы работы, получает инвестиции и принимает участие в проектах, финансируемых частным бизнесом.

В рамках реализации Национального плана действует Фонд венчурного капитала, осуществляющий финансирование молодежных инновационных проектов. Однако доступ к финансовым ресурсам, предоставляемым Фондом, весьма ограничен.

С 2017 года Национальным молодежным секретариатом при поддержке ЮНЕСКО и Бразильского форума общественной безопасности реализуется программа Youth Living, которая также направлена на развитие предпринимательства и инноваций среди бразильской молодежи. Программа предусматривает проведение теоретических и технических тренингов, предоставление специализированной технической помощи по вопросам реализации бизнес-проектов.

С 2012 года в Бразилии реализуется программа «Молодежная станция» [8], направленная на удовлетворение потребностей молодежи путем предоставления бесплатных общественных помещений, информационного обеспечения во всех регионах Бразилии. Программа, финансирование которой составило 11 млн. реалов, осуществляется при поддержке государства и муниципалитетов и позволяет обеспечить доступ бразильской молодежи к участию в жизни общества.

В целях поощрения развития науки среди молодежи Бразилии в 2016 г. Национальным секретариатом и Национальным советом молодежи при участии научного сообщества и университетов, была создана молодежная библиотека, а в 2017 г. сформированы ее цифровые активы, позволившие расширить доступ молодежи к знаниям и научным исследованиям (в том числе из зарубежных источников) с помощью бесплатного программного обеспечения DSpace.

С 2019 года в стране реализуется пакет из 12 инициатив, направленных на содействие развитию молодежи в возрасте от 15 до 29 лет. Пакет включает 91 программу, распространяющуюся на 51 миллион молодых бразильцев.
Взаимодействие молодежи с университетами и бизнес-структурами в области НИОКР в Бразилии весьма скромно. Данный факт влияет на низкую способность генерирования знаний и инноваций в деловую среду. Вместе с тем, следует отметить, что университеты Бразилии прикладывают значительные усилия для предоставления молодежи академических научных знаний.

В Индии молодежью признается население в возрасте от 15-29 лет и ее численность составляет $27,5 \%$ населения. Ключевые направления формирования молодежной политики Индии закреплены в документе 2014 г. «Национальная молодежная политика» и пятилетнем плане работы с подростками и молодежью на 20182023 гг. Согласно названным документам, молодежная политика страны направлена на создание производительной рабочей силы, способствующей экономическому развитию; создание условий роста здорового поколения; продвижение социальных ценностей; содействие развитию гражданской позиции гражданина; оказание поддержки молодежи, находящейся под угрозой и создания равноправных условий для всех обездоленных молодых людей.

Анализ способов реализации данных планов подтверждает, что основной акцент делается на образование, ликвидацию нищеты и голода, занятость, вовлечение в предпринимательскую деятельность и вовлечение в спортивные мероприятия.

Основной сферой деятельности индийской молодежи является сельское хозяйство, что обеспечивает 50\% вклада в общую занятость. В этой связи молодежная политика Индии ориентирована не на развитие инновационных технологий, а на обучение молодежи современным методам ведения сельского хозяйства. Тем не менее, молодежная политика также включает требования к развитию цифровых навыков молодого поколения и направлена на развитие квалифицированной и индустриальной молодежи. Однако отдельных документов, обеспечивающих данные направления реализации молодежной политики, автору исследования выявить не удалось.

89\% молодых людей Индии не имеет профессионального образования, что объясняется невысокими расходами государства на образование (немногим более 4\% ВВП). Это обеспечивает 84-ю позицию государства по данному показателю в мире [6]. Исполнительным органом власти, координирующим молодежную политику в области образования, жилищного обеспечения, добровольчества и спорта является Министерство молодежи и спорта. Министерство финансирует Национальный институт развития молодежи им. Раджива Ганди, который 
является научным центром, реализующим молодежную политику страны.

В целом, правительство Индии инвестирует более 90000 рупий в год на реализацию молодежных программ и более 2710 рупий на одного молодого человека в год в целях обеспечения молодежи высшим образованием, здравоохранением (целевые статьи расходов) и питанием, трудоустройством (нецелевые статьи расходов) [6].

Финансирование, в основном, предоставляется в форме грантов в государственные школы и университеты и распределяется в виде прямых денежных пособий ученикам или стипендий студентам. Кроме того, финансированию подлежат программы, ориентированные на молодежь в области обеспечения занятости и поддержки здоровья [12].

Kuтай. В Китае отсутствуют зафиксированная на законодательном уровне единая национальная молодежная политика или официальный механизм исполнительной власти по проведению и мониторингу национальных и региональных вопросов по делам молодежи. Молодежная политика рассматривается как компонент общей государственной политики и предусмотрена в законах, правилах и положениях. Молодежная политика направлена на вовлечение молодых людей в процесс социалистического, экономического, политического, культурного и социального строительства через развитие способностей, творчества, гражданской ответственности и трудолюбия.

Несмотря на отсутствие отдельного документа, регламентирующего молодежную политику, в Китае разработан закон «О молодежи Китая» который формулирует ключевые принципы поддержки молодого населения, регламентирует первоочередные меры в области обеспечения рабочими местами и жильем, поддержки молодых семей, выплаты пособий по безработице, мероприятий по охране здоровья и пр. Реализацию молодежной политики обеспечивает Коммунистический союз молодежи Китая, который является представителем политики партии и проводит обучение молодежи социализму и коммунизму.

Современная молодежная политика, проводимая Китаем, кроме активной идеологической составляющей, нацелена на вовлечение молодежи в трудовую деятельность. Так, широко распространенные в стране летние трудовые лагеря привлекают молодежь к сельскохозяйственным работам на платной основе, в результате чего у молодежи формируются навыки коллективной работы, а также базовые профессиональные компетенции [9].

Ввиду ускорения интеграции Гонконга и Макао в материковый Китай и быстрого развития глобализации, в Китае поощряются и поддерживаются программы обмена молодежи. Активное распространение получили такие мероприятия молодежной политики, как «Фестиваль китайских драконов», «Молодежный фестиваль по пересечению пролива», «Молодежный форум по проливам» и другие. Также Китай устанавливает дружеские отношения с зарубежными организациями по работе с молодежью и организует многочисленные международные молодежные программы обмена [9].

Одним из ключевых мероприятий молодежной политики в области науки, техники и инноваций по праву считается Конкурс инноваций в области науки и технологий китайской молодежи (CASTIC) от 12 до 20 лет. Конкурс проводится Китайской ассоциацией науки и технологий CAST, Министерством образования и другими правительственными организациями. Более чем 30-летняя история CASTIC позволяет ежегодно привлекать свыше 500 китайских молодых ученых и 100 международных участников из более чем 20 стран мира с представлением научных проектов, участвующих в 13 номинациях. Конкурс проводится при тесном взаимодействии с AMAVET (Словакия), Astra (Датский научный завод), Creative Industries (Австралия), Association of Scientific and Technical Societies (Чехия), Engineering (Великобритания), Fondation Jeunes Scientifiques (Люксембург), Association for Innovation (Венгрия), Invention and Innovation Promotion Association (INNOPA) (Индонезия), Science and Technology Agency (JST) (Япония), Jugend Forscht (Германия), Foundation for the Advancement of Science and Creativity (KOFAC) (Кopeя) и т.д.

Китайский ученики средней школы занимают призовые места на международных научных конкурсах. Так, в 2018 году на копенгагенской Ярмарке молодых ученых, представители молодежи Китая подтвердили свою научную подготовку и стали победителями, представив проекты «Исследование системы сканирования лазерного гальванометра с помощью GCode и 3D печати», «Изучение новых технологий возвращения чистой воды» и «Многоступенчатый импульсный электромагнитный ускоритель» [10].

С 1987 года в целях поощрения молодых специалистов в области науки и техники Китайской научной и технической ассоциацией присуждается Молодежная научная и техническая премия.

Таким образом, можно утверждать, что в Китае проводится продуктивная работа с молодыми дарованиями в самых разных областях науки и техники. Однако, большинство лучших выпускников китайских колледжей и университетов предпочитают работать за рубежом. Так, доля выпускников вузов, уезжающих за гра- 


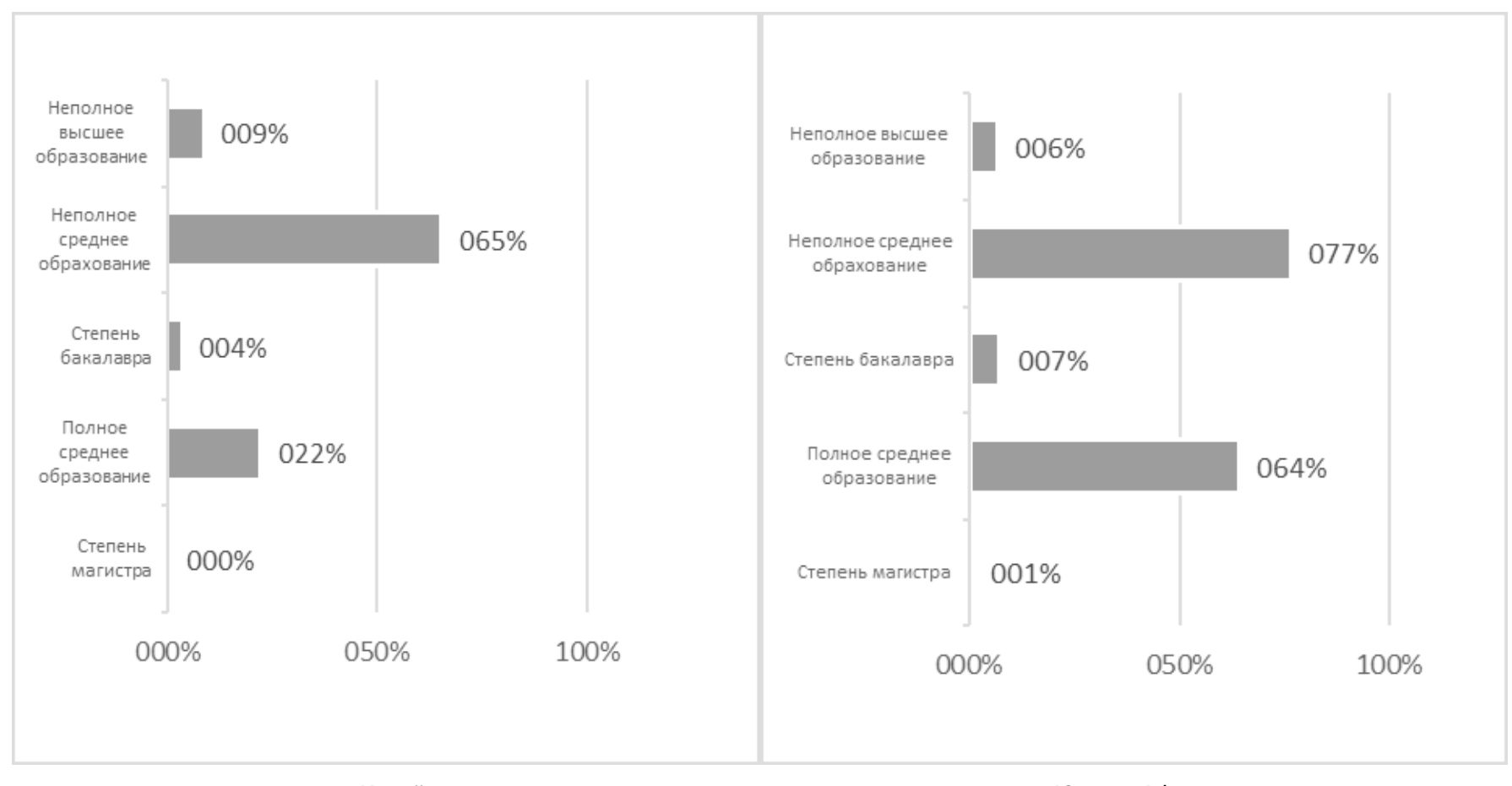

Китай

Южная Африка

Рис. 1. Уровень образования жителей Китая и Южной Африки [6].

ницу, составляет 17,5\%. Таким образом, инновационные результаты работы китайской молодежи, в основном, применяются за пределами своего государства. Одной из причин таких предпочтений китайской молодежи может служить достаточно высокий уровень безработицы, который составляет около $11 \%$.

Переезд молодых талантов за рубеж является серьезной проблемой, которая стоит перед китайским сообществом. В целях ее предотвращения правительство Китая проводит ряд мероприятий, которые ставят своей целью «сохранение» талантливой молодежи на территории страны - это и программа «Тысяча талантов», и «Выдающийся молодежный фонд» и др.

Южно-Африканская Республика. Концепция развития молодежи в Южной Африке основана на исторических традициях, принципах социальной и экономической справедливости, расширении прав и возможностей граждан, поощрении общественных благ и либеральных ценностей.

Национальная молодежная политика Республики разрабатывается с 2009 года. В настоящее время действует документ, регламентирующий моложеную политику на 2015-2020 годы (NYP-2020) [11], и в котором представлены меры, направленные на обеспечение участия молодежи в преобразовании национальной экономики.
Таким образом, целью молодежной политики, проводимой ЮАР в настоящий момент, является консолидация инициатив, которые расширяют возможности молодых людей по преобразованию экономики и общества. Данная цель будет достигнута при условии удовлетворения потребностей молодого поколения и оказания многосторонней поддержки, необходимой для его развития.

NYP-2020 является частью законодательной и политической платформы, которая определена следующим документами:

- Конституцией Южной Африки (1996 г.). Конституция закладывает основу для расширения экономических прав и возможностей молодежи и закрепляет права людей (в том числе молодежи) на равенство и свободу;

- Национальным планом развития Южной Африки (NDP) до 2030 года, который ориентирован на развитие молодежных программ.

Национальный план развития включает следующие предложения:

- обеспечение всеобщего доступа к начальной школе, в том числе увеличение количества обучающихся и повышение уровня грамотности;

- внедрение новых молодежных программ, направленных на обучение предпринимательству;

- увеличение числа организаций, участвующих в дополнительном образовании, предоставле- 
ние финансовой помощи студентам из малообеспеченных семей и создание центров общественной безопасности для предотвращения преступности;

- создание налоговых стимулов для работодателей в целях привлечения молодежи к труду;

- обеспечение доступности учебных ваучеров для лиц, ищущих работу;

- введение формализованной системы найма выпускников для государственной службы;

- расширение роли государственных предприятий в подготовке специалистов.

Направленность молодежной политики ЮАР определяется социально-экономическим положением страны, уровнем развития образования, которое под данным Всемирного банка, превышает показатели Китая (рисуHOK1).

Вместе с тем, по данным основных направлений молодежной политики до 2020 года, грамотность и навыки счета на уровне начальной школы в ЮАР значительно ниже среднего международного. Низкий уровень знаний препятствует получению высшего образования, особенно в области науки и техники. В этой связи направления молодежной политики в разрезе развития науки и техники стратегических документах не рассматриваются, а концентрируются на устранении безработицы и обеспечении доступа к качественным медицинским услугам.

Меры, принимаемые государством в целях снижения безработицы (инвестиции в инфраструктуру) способствовали увеличению занятости молодежи в экономике (созданы 30701 постоянных рабочих мест, более 30 000 молодых людей обеспечены стажировки и обучение на государственной службе, улучшилось качество высшего и дополнительного образования, наблюдается заметный прогресс в получении технических и средних профессиональных навыков среди молодежи [6].

Департамент торговли и промышленности и Департамент развития малого бизнеса разработали Стратегию развития молодежного предпринимательства (NYDA), в рамках которой предоставляется поддержка в виде залогового обеспечения молодым компаниям. Благодаря NYDA, реализуются программы стимулирования моло- дежных предприятий, занимающихся вопросами развития, обучения и реализации рыночных связей.

Однако подобная поддержка фрагментарна и слабо коррелирует с другими стратегическими документами, разработанными в ЮАР. Несмотря на то, что на развитие молодежного предпринимательства различными структурами расходуются значительные суммы денег, предоставляемая поддержка недостаточна.

Научная деятельность в ЮАР направлена на осуществление исследований и разработок (НИОКР) в стратегических и новых приоритетных областях (космическая наука, энергетика, биотехнологии, нанотехнологии, робототехника), а также в сфере управления интеллектуальной собственностью, коммерциализация технологий в целях содействия реализации коммерческих продуктов, процессов и услуг из результатов НИОКР посредством внедрения инструментов стимулирующей политики [13]. Однако отдельного документа, описывающего участие молодого поколения в научных, технических и инновационных мероприятиях, в ЮАР не предусмотрено.

\section{Выво $\triangle \mathrm{b}$}

Безусловный интерес для Российской Федерации вызывают программы, нацеленные на вовлечение молодежи в инновационные методы работы, получение молодыми предпринимателями инвестиций и активное участие в проектах, финансируемых частным бизнесом. Опыт стран БРИКС, осуществляющих финансирование талантливой молодежи, обучающейся в школах и высших учебных заведениях, за счет грантов в виде прямых денежных пособий ученикам или стипендий студентам, можно рассматривать как формирование мотивации к научным знаниям молодежи в регионах, снизить социальную напряженность и повысить занятость на отдаленных от федерального центра территориях. В целях повышения эффективности расходов на развитие молодежного предпринимательства необходимо провести всесторонний обзор существующих программ поддержки в государственном и частном секторах, при этом особое внимание следует уделять молодежи в сельских районах, изучить и разработать отраслевые инкубаторы в этих регионах.

\section{ЛИТЕРАТУРА}

1. Грузина Ю.М., Мельничук М. В. Анализ зарубежного опыта по формированию и развитию молодежной политики в сфере образования, науки и инноваций // Российский гуманитарный журнал. 2018. Т. 7. № 6. С. 452-463.

2. Маковеев В. Н. Стимулирование инновационной деятельности в странах БРИКС // Вопросы территориального развития. № 2 (32). 2016. С. 1-11.

3. Мельничук М.В., Грузина Ю. М., Фирсова И. А. Формирование научно-образовательных ценностей в системе мотивации молодежи. // Экономические и социальные перемены: факты, тенденции, прогно3. 2019. Т. 12. № 6. С. 260-275. 
4. Молодежный устав Республики Бразилия [Электронный ресурс].— Режим доступа: http://www.planalto.gov.br/ccivil_03/_Ato2011-2014/2013/Lei/ L12852.htm

5. Национальный план развития стартапов для молодежи [Электронный ресурс].—Режим доступа: http://juventude.gov.br/articles/participatorio/0022/4166/ Plano_Nacional_de_Startups_VISUALIZA_0_2007.pdf

6. Официальный сайт Всемирного банка [Электронный ресурс]. — Режим доступа: http://data. worldbank.org

7. План социально-экономического развития Китая на 2016-2020 гг. [Электронный ресурс].— Режим доступа: https://en.ndrc.gov.cn/ newsrelease_8232/201612/P020191101481868235378.pdf

8. Программа «Молодежная станция» [Электронный ресурс].— Режим доступа: http://juventude.gov.br/juventude/programas/programa-estacao-juventude

9. Alessia Amighini. China Dream: Still Coming True? 2016. Edizioni Epoké ISBN-13: 978-8899647179

10. Chinese Students obtained good results in 2018 Young Scientists Fair and Contest. Available at: http://www.cyscc.org.cn/News/newsView.aspx? Type $=$ index\&AID $=223218$

11. National Youth Policy 2015-2020. Available at: http://www.youthpolicy.org/national/South_Africa_2015_National_Youth_Policy.pdf

12. Raj. M, Casimir. (2017). Youth Policy of India: Critical reflections. Critical reflections. 2017. ISBN978-81-929640-7-2 Don Bosco Youth Animation South Asia (DBYA$\mathrm{SA})$

13. Technology innovation. Available at: http://www.dst.gov.za/index.php/programmes/technology-innovation

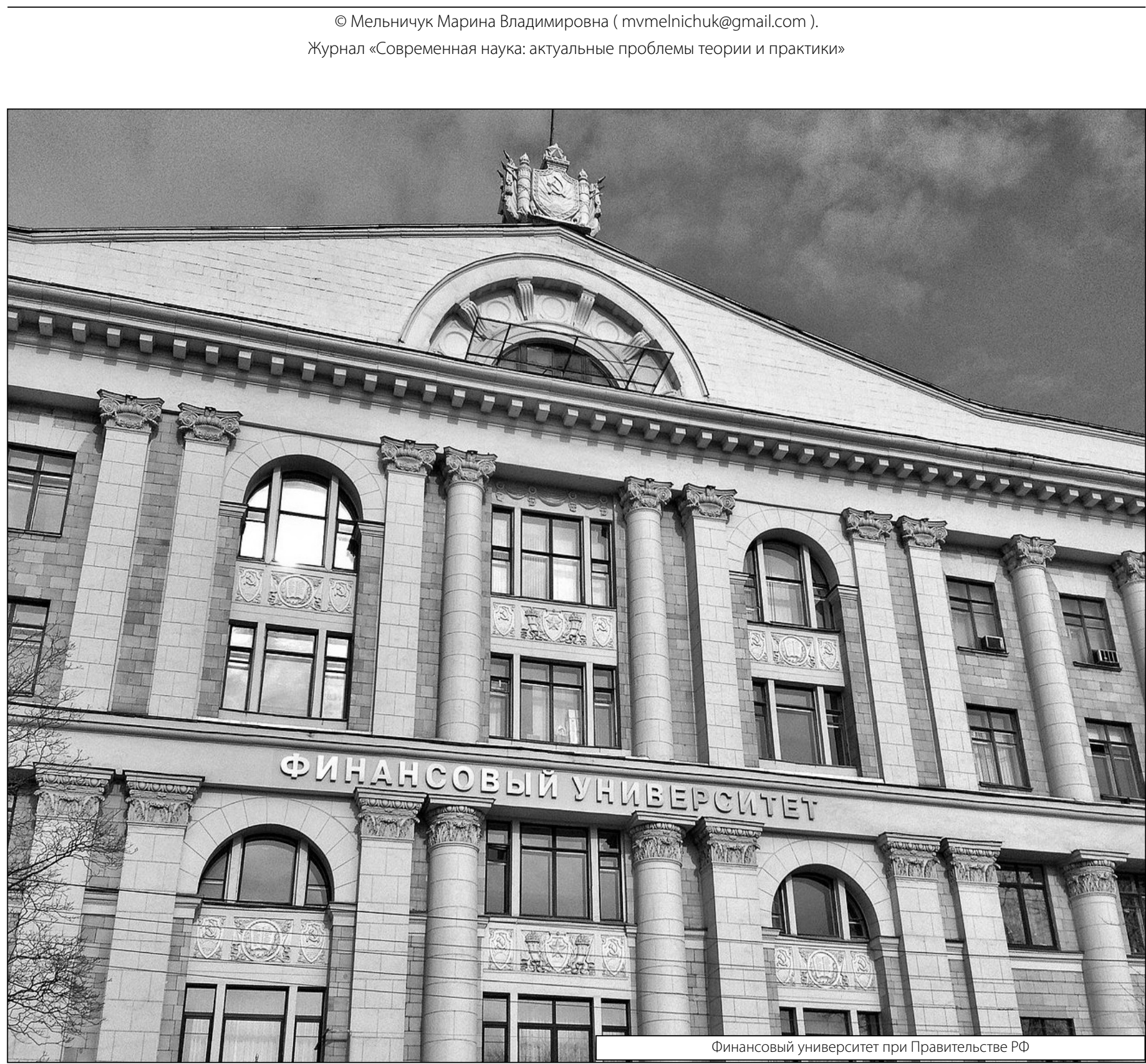

